\title{
Beyond BMI: waist circumference and social environment is associated with motor performance ability in kindergartners
}

\author{
Sascha W. Hoffmann ${ }^{1,2 \dagger}{ }^{\dagger}$, Matthias Dreher ${ }^{1 \dagger}$, Michael S. Urschitz ${ }^{3}$ and Perikles Simon ${ }^{1 *}$ (D)
}

\begin{abstract}
Background: The aim of the current study was to examine the relationship between anthropometric characteristics (i.e. body height, body weight, body mass index [BMI] and waist circumference [WC]) with motor performance ability [MPA], social environmental factors of the district (i.e. employment status/working life, education, social situation/heterogeneity and home environment), where the respective kindergarten was located, as well as other potential health determinants in a representative sample of kindergartners.

Methods: We analyzed data of 434 children aged 3 to 6 years which were obtained from a community-based cross-sectional health study conducted in the city of Mainz, Germany. Body height and weight, BMI and WC standard deviation scores [SDS] were calculated relative to the international proposed cut-offs of the IOTF. MPA was collected with multiple test items to determine coordination, speed strength, muscular endurance and speed. The life situation index [LSI] was used to assess the social environment of the district of the kindergarten. Adjusted for covariates, correlation and logistic regression analyses were conducted to estimate the effect of WC on MPA.
\end{abstract}

Results: Below-average MPA was found in $46 \%$ of the sample. While there was no relationship to BMI (odds ratio [OR]: 1.09, 95\% confidence interval [95\% Cl]: 0.83-1.44; $p=0.538$ ), WC SDS was positively associated with belowaverage MPA (OR: 1.41, 95\% Cl: 1.01-1.95; $p=0.041)$. Further results show that the social environment of the district of the kindergarten was independently related to below-average MPA (OR: 2.72, 95\% Cl: 1.29-5.75; $p=0.009$ ).

Conclusion: The findings suggest that WC rather than BMI is linked to measurements of MPA already in kindergartners and furthermore, there seems to be an independent association between MPA and the social environment of the district of the respective kindergarten.

Keywords: Overweight, Obesity, Kindergartners, Body mass index, Waist circumference, Social environment, City District

\section{Background}

The increase of overweight/obesity in childhood is a major public health concern [1-3]. The worldwide estimated prevalence of overweight/obesity in children in 2010 was $6.7 \%$ and is expected to reach an estimated $9.1 \%$ in 2020 , which would affect about 60 million children [4]. Depending on the country, the prevalence might be much higher. For example, 23\% of Australian preschoolers between 2

\footnotetext{
* Correspondence: simonpe@uni-mainz.de

${ }^{\dagger}$ Sascha W. Hoffmann and Matthias Dreher contributed equally to this work. 'Department of Sports Medicine, Disease Prevention and Rehabilitation, Faculty of Social Science, Media and Sport, Johannes Gutenberg-University Mainz, Albert-Schweitzer-Straße, 22, 55128 Mainz, Germany

Full list of author information is available at the end of the article
}

and 4 years are overweight/obese and boys in the age of 5-7 year show the highest obesity rate [5]. Between 1975 and 2016 global age-standardized mean body mass index (BMI) in children and adolescents aged 5-19 years varied widely by region and decade, while BMI increased gradually over the four decades of analysis. However, a recent flattening of trends was observed in northwestern Europe and the high-income English-speaking Asian-Pacific region for both genders; in southwestern Europe for boys and in central and Andean Latin America for girls [6].

The reasons for being overweight or obese in childhood are very diverse. On the one hand, the well-known risk factors like low physical activity, high sedentary

(c) The Author(s). 2020 Open Access This article is distributed under the terms of the Creative Commons Attribution 4.0 International License (http://creativecommons.org/licenses/by/4.0/), which permits unrestricted use, distribution, and 
activity, high screen time activity, unhealthy diet, inadequate sleep, psychological factors and a disadvantageous built environment have been widely studied, summarizing an increased risk of the development of overweight/obesity [7-11]. On the other hand, additive influence factors like the social environment, living situations, demography, budgetary structure, income maintenance, marginalized social groups, social structures in general, and educational aspects are less studied but play a potential role in shaping overweight/ obesity risk $[8,12,13]$.

Apart from the increase in childhood overweight/obesity, motor performance ability (MPA) deficits in children have significantly increased during the last decades, even in Germany [14-21]. MPA has deteriorated by an average of $10 \%$ [22]. Research suggests that childhood obesity may lead to impaired cognitive and physical development which could trigger a cycle of physical activity avoidance and reduced social interactions in later childhood [23]. Prior research on the association between obesity and impaired MPA shows conflicting results. While some studies and a systematic review [24] found impaired MPA in overweight/obese children independent of gender [25-27], other studies just showed reduced MPA amongst obese boys compared to non-obese boys [28, 29]. National representative data of MPA in children was provided by the "Motorik-Modul” (MoMo) conducted as a sub-survey of the German Health and Examination Survey of Children and Adolescents (KiGGS) [18, 20, 30]. Among the 4-11year old children, girls showed a slightly higher motor fitness than boys. Additionally, the results indicated an association between motor fitness, migration background and socio-economic status [30]. Higher fundamental movement skills in boys compared to girls are well documented [31]. Overall, the results emphasize the relevance of an early focus on motor ability improvement to encourage overweight/obese children to be physically active [25]. The protective effect of fitness and motor competence to avoid overweight/obesity has already been shown [32].

However, tailored prevention strategies to improve children's health and motor ability performance will be more effective, if representative community-based data is available. Although such data has been assessed in different parts of Germany; no data is available for the state of Rhineland-Palatinate [15, 16, 26, 33-38]. In addition, little is known about the relationship between anthropometric measurements and MPA at pre-school age [16] and published data was only related to BMI $[25-27,39,40]$. A systematic review reported only one article which assessed waist circumference (WC) in relation to fundamental motor skills [41]. In recent years, research suggests using other overweight-related variables rather than BMI for the prognosis of cardiovascular outcomes. BMI was shown to provide lower predictive ability and is seriously flawed, because it does not distinguish fat mass from fat-free mass $[42,43]$. WC, in contrast, seems to be a better predictor of abdominal obesity in children [44]. Considering recent research, the main aim of the present study, was to analyze whether WC is better associated with MPA in kindergartners than BMI.

\section{Methods}

\section{Data source}

The present study is based on data of the Children Health Study of Mainz (CHSM) [45]. Parents of children attending one out of 34 of the 35 regional public kindergartens were informed and invited to participate in the CHSM. The purpose of the study was to collect data about health determinants associated with overweight/obesity in preschool children and their related caregivers [45]. Children were also invited to participate in assessments of anthropometry measurements and MPA tests.

Of 869 parents contacted, 558 replied to our invitation and filled out a questionnaire. Six children were excluded because they lived with their grandparents, foster or adoptive parents. A further 81 were excluded due to incomplete information about body height and weight and their habitual physical activity scores. In addition, thirty-seven children were excluded due to inability to perform the MPA tests $(n=35)$ and the absence of WC measurements $(n=2)$. Thus, complete data was available from 434 parent-child pairs. For inclusion in the present study, children had to be free from acute and infectious diseases, chronic diseases and restrictions related to the active and passive musculoskeletal system. A detailed description of the active recruitment strategy is presented elsewhere [45]. Participation in this study was voluntary and all parents of participants provided written informed consent. To increase the level of anonymity, personal data collection was reduced to a minimum.

\section{Questionnaire}

One of the child's primary guardians completed a selfconstructed standardized paper and pencil questionnaire. During informative meetings about the aims and procedures of the study in each kindergarten, parents were informed about the MPA screening of their child, about the health benefits of regularly conducted physical activity, especially in the family environment, and furthermore about the potential early life determinants of overweight/obesity [3]. Essentially, the questionnaire consisted of two main parts. The first part asked about children's sociodemographic and anthropometric data like age, gender, height and weight at birth as well as questions about the current health status and language which is primarily spoken by the child and the parents. According to Rapp et al. [46], participants responded when they picked up their child from kindergarten to 
calculate daily time children attended the kindergarten. Additional questions were asked about physical activity habits and screen time activity (characterized with daily TV time and using the PC/Internet on weekdays/weekends) $[47,48]$. Children's physical activity level was assessed using a modified Baecke Habitual Physical Activity Questionnaire (HPAQ) [49] in which parents reported about their child's physical activity behavior [50,51]. Questions about screen time activity have already been used in the German Health Interview and Examination Survey for Children and Adolescents (KiGGS) [48, 52]. Detailed information of the raised questions and all classifications regarding habitual physical activity level and screen time activity were presented in a previous publication [45].

The second part focused on parental anthropometric characteristics (age, gender, weight, height), cultural background (country of birth, nationality), educational and employment level, alcohol intake, and smoking status. Parental BMI was calculated according to the WHO criteria [53] and education level was used to represent the individual socio-economic position (SEP) and was categorized into three levels: low educational level (primary school or none), middle educational level (vocational secondary modern school or equivalent), as well as high educational level (university or vocational postsecondary school) [54].

\section{Assessment of anthropometric measurements in children and definition of overweight/obesity}

Children's height and weight was measured by trained staff with a calibrated portable stadiometer (SECA 217 [SECA, Hamburg, Germany]) and with a calibrated flat scale (SECA 803). Children were weighed without shoes and wore light clothes. WC was measured according to proposed international proceedings [55-58] using an inelastic tape (SECA 203).

Overweight/obesity were defined according to the IOTF international proposed age- and gender-specific cut-offs. The IOTF cut-offs and international thinness cut-offs are used to classify children aged $2-18$ years as thin, normal weight, overweight or obese, based on adult BMI cut-offs at 18 years [59]. BMI and WC SDS were calculated according to the international commonly used UK 1990 reference [60-62]. WC risk groups were categorized using German WC reference values obtained in 3-11 years old children [57]. Due to the fact that WC is a highly sensitive marker for abdominal obesity in childhood [44, 57, 63] and other anthropometric characteristics (i.e. weight, height, BMI) tend to underestimate obesity in youth [64], two modified risk groups in accordance with Schwandt et al. [57] were used: (1) No risk (<90th percentile) and (2) High risk of having multiple cardio-metabolic risk factors (MCRF; 90th $<97$ th percentile).

\section{Assessment of motor performance ability [MPA]}

MPA of coordination, speed strength, muscular endurance and speed was assessed with multiple test items (One leg stand, standing long jump, lateral jump) of the modified Karlsruher Motor Ability Screening Test (KMS 3-6) [35], the Motorik Modul of the KiGGS-Study [18] and the KiMo project [16]. Reliability and validity of the test items ( $\mathrm{r}$ ranging from 0.8 to 0.9 ) have been shown previously [35].

The following criteria have been applied for selection of test items [15]:

- Economy of feasibility

- Greatest possible acceptability by study participants

- Correlative relationships with health-related questions

Additionally, the "shuttle run" test, already conducted by Krombholz in 2004 [36], was employed to depict the MPA of speed. Due to the possibility of methodical difficulties which may arise in carrying out the "one leg stand" on a bar with a width of $3.0 \mathrm{~cm}$ at pre-school age, one leg stand was performed on a bar with a width of $4.5 \mathrm{~cm}$ in accordance with Krombholz [36] and De Toia et al. [16]. All test results were classified according to the summarized age and gender-specific reference values $[16,35,36]$. Due to the fact that there were no significant differences between normal weight and overweight/ obese children in the test item "sit and reach" in the proposed age groups [20], this test item was omitted.

MPA tests were conducted in each kindergarten during mid-morning and each child was instructed by one trained member of the staff.

A detailed description of the test items with information about material, test construction and realization was published elsewhere [65]. Data collection generally took 1012 min per child and each staff member demonstrated the tests before the child performed the test. There was no special order for the test items and up to four children performed the tests simultaneously, depending on the respective spatial conditions in the test room.

\section{Social environment of the district of the kindergarten}

Regarding the social environment, we examined if kindergartners who attended kindergartens which are in socially deprived city districts were more likely to be overweight or obese. As part of a social city district analysis conducted by Pfeiffer et al., [66] comprehensive information about general conditions (land use, current living situation, demography, budgetary structure, employment status of the family and income maintenance) and social structures (highly problematic family status and educational level) were collected from each city district of the city of Mainz. This led to the computation of a Life Situation Index (LSI) based on employment status/working 
life, education, social situation/heterogeneity and home environment, summarized to one scale and which we used in this study. Detailed description and method of calculation for demonstrating socio-demographic and socioeconomic differences are presented in our previous studies $[45,47]$.

\section{Statistical analysis}

Descriptive anthropometric characteristics were presented as means, frequencies and percentages with standard deviations (SD), respectively. The results of the MPA test items of the children were calculated for the total sample for gender, BMI groups, WC risk groups and LSI groups and were presented as medians and interquartile range (IQR). The software package LMSgrowth, Version 2.77, was used to calculate age and gender-specific standard deviation scores of height, weight, BMI and WC. For details of the methods we refer to previous publications $[59,67,68]$.

For the MPA test results, we conducted group comparisons between boys and girls and normal weight and at least overweight children, as well as between WC risk groups and the LSI groups of each kindergarten using the Mann-Whitney U-Test.

In addition, descriptive characteristics of the final parental reports were employed and stratified by gender. Product-moment correlation coefficients, adjusted for age, BMI SDS and WC SDS, migration background, LSI and parental BMI were calculated to analyze the relationship between the MPA test items and the indices of children's physical activity and investigate the associations between the indices of children's physical activity and the indices of physical activity of their parents.

The association between potential determinants and MPA was examined using multiple logistic regression analysis and odds ratios (ORs) and the corresponding 95\% confidence intervals $(95 \% \mathrm{CI})$ were calculated. Continuous variables were categorized. JMP 8.0 (SAS, Cary, NC) and SPSS PASW 22 Statistics (IBM Corp., Somers, NY) were used for statistical analyses. Overall power analyses indicated a power ranging from 97 to $99 \%$ with $p$ values below 0.05 .

\section{Results}

\section{Sample characteristics}

Table 1 presents the descriptive characteristics of the study sample. Mean age ( \pm SD) was $4.9 \pm 1.0$ years and $55.9 \%$ were boys. Girls were significantly older $(p=0.009)$ than boys, whereas BMI was higher in boys $(p=0.043)$. Prevalence of overweight/obesity was significantly higher in boys than in girls $(p=0.027)$. In summary and according to the IOTF cutoffs, $18.1 \%$ were overweight/obese.
Table 1 Descriptive characteristics (Mean $\pm S D^{\mathrm{a}}$ ) of the total study sample stratified by gender

\begin{tabular}{llll}
\hline Item & Boys & Girls & Total \\
\hline $\mathrm{N}$ & 243 & 191 & 434 \\
Age & $4.8 \pm 1.0$ & $5.0 \pm 1.0$ & $4.9 \pm 1.0$ \\
Height, cm & $109.8 \pm 7.8$ & $110.5 \pm 8.5$ & $110.1 \pm 8.3$ \\
Height SDS & $0.5 \pm 1.1$ & $0.4 \pm 1.0$ & $0.4 \pm 1.0$ \\
Weight, kg & $19.6 \pm 3.8$ & $19.4 \pm 3.5$ & $19.5 \pm 3.7$ \\
Weight SDS & $0.5 \pm 1.1$ & $0.3 \pm 0.9$ & $0.4 \pm 1.0$ \\
BMl, kg/m ${ }^{2}$ & $16.2 \pm 1.6$ & $15.8 \pm 1.4$ & $16.0 \pm 1.5$ \\
BMI SDS & $0.3 \pm 1.2$ & $0.1 \pm 0.9$ & $0.2 \pm 1.0$ \\
Waist circumference, cm & $53.3 \pm 4.2$ & $52.6 \pm 3.6$ & $53.0 \pm 4.0$ \\
Waist circumference SDS & $0.4 \pm 1.1$ & $0.4 \pm 0.9$ & $0.4 \pm 1.0$ \\
Thinness grade I, \% (n) ${ }^{\mathrm{b}}$ & $4.9(12)$ & $6.3(12)$ & $5.5(24)$ \\
Normal weight, \% (n) & $72.8(177)$ & $81.2(155)$ & $76.5(332)$ \\
Overweight, \% (n) & $15.6(38)$ & $11.0(21)$ & $13.7(59)$ \\
Obese, \% (n) & $6.6(16)$ & $1.6(3)$ & $4.4(19)$ \\
\hline
\end{tabular}

${ }^{\mathrm{a}} \mathrm{SD}=$ Standard deviation

${ }^{\text {b}}$ Thinness grade I-III were combined into one single thinness grade I due to small sample size

Total available parental characteristics concerning age, body height, body weight, calculated BMI with respective BMI groups, smoking status, country of birth, nationality and SEP from the questionnaire by males and females are presented elsewhere [45]. Results of the final parental sample descriptions of the items of habitual physical activity, screen time activity as well as the overweight/ obesity status and the perception of weight status and associated health risks stratified by gender are also presented elsewhere [45]. The majority of parents analyzed in the final sample $(n=434)$ were female $(85.7 \%)$. Indices of habitual physical activity did not differ between genders. Prevalence of overweight was higher in responding fathers compared to mothers (53.3 to $35.4 \% ; p=0.008$ ). Moreover, responding fathers had higher PC/Internet use on weekends than mothers $(p=0.007)$.

\section{Motor performance ability [MPA]}

Below-average MPA was found in $46 \%$ of the total sample, while this was present in $59.2 \%$ of the children for the one leg stand, in $27.4 \%$ of the children for the standing long jump, in $31.6 \%$ of the children for lateral jumping, and finally in $46.0 \%$ of the children for the shuttle run test (see Fig. 1).

As shown in Table 2, girls had significantly less floor contacts than boys in the test item "one leg stand" $(P<$ 0.001 ). No differences were found in the test items "standing long jump", "lateral jumping" and "shuttle run". Regarding the relationship of MPA and BMI status, Table 3 shows that significant BMI group differences were only observed within the test item "lateral jumping" between children classified into normal weight and overweight/ 


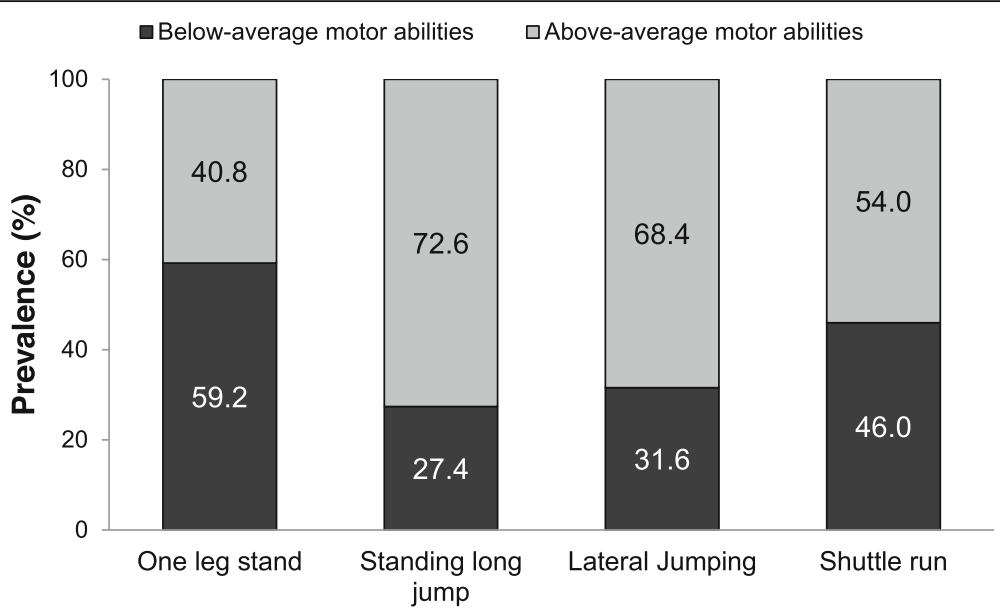

Fig. 1 Relative frequencies of below-average and above-average motor ability in kindergartners aged 3 to 6-years

obesity. Overweight/obese children performed significantly less jumps than children in the normal weight group $(21.6 \pm 12.1$ vs. $29.4 \pm 12.2 ; p=0.039)$.

In contrast to this, significant differences between the no risk WC group and the group with high risk of having multiple cardio-metabolic risk factors in all test items except in the "shuttle run" were observed (see Table 4).

Table 5 shows the relationship of motor ability performance and the social environment of the district of the kindergarten expressed as two LSI groups. Significant group differences between LSI groups were observed in the test

Table 2 Motor performance ability test items (Median and IQR ${ }^{\mathrm{a}}$ ) of the total study sample stratified by gender

\begin{tabular}{lll}
\hline Test items & Median (IQR) & $P^{*}$ \\
\hline One leg stand (floor contacts; $\mathrm{n}=434)$ & $<\mathbf{0 . 0 0 1}$ \\
Boys & $21.0(10.0$ to 30.0$)$ & \\
Girls & $13.0(7.0$ to 30.0$)$ & \\
Total & $17.0(7.0$ to 30.0$)$ & \\
Standing long jump (cm; $\mathrm{n}=434)$ & \\
Boys & $84.0(63.0$ to 103.0$)$ & \\
Girls & $85.0(67.0$ to 103.0$)$ & \\
Total & $85.0(65.0$ to 103.0$)$ & \\
Lateral jumping (jumps; $\mathrm{n}=434)$ & 4.156 \\
Boys & $23.0(18.0$ to 30.0$)$ & \\
Girls & $25.0(19.0$ to 31.0$)$ & \\
Total & $24.0(18.0$ to 31.0$)$ & \\
Shuttle run (s; $n=424)$ & $10.5(9.1$ to 12.1$)$ & \\
Boys & $10.6(9.5$ to 12.3$)$ & \\
Girls & $10.6(9.3$ to 12.2$)$ & \\
Total &
\end{tabular}

${ }^{*} P<0.05$; Mann-Whitney U-Test for gender differences; significance printed in bold type

${ }^{\mathrm{a}} \mathrm{IQR}=$ Interquartile range items "one leg stand" ( $p=0.044)$ and "standing long jump" $(p=0.043)$.

Determinants of below-average motor ability from multiple regression analysis are shown in Table 6. The final regression model indicated that BMI was not integrated in the final model and it seems that in kindergartners $\mathrm{WC}$ is a better predictor of motor ability than BMI. Analyses furthermore indicated that older children performed better in motor ability tests than their younger counterparts; hence, younger children were at higher risk for belowaverage motor ability than older children. Additionally, the social environment of the district of the kindergarten was significantly positive related to below-average motor ability. Finally, there were additional positive associations with parental sport index as well as with children's sport and leisure-time index (data not shown).

\section{Discussion}

Results of the present study revealed determinants of below-average motor performance ability in a sample of 3-6-year-old kindergartners.

Significant determinants of below-average motor ability were being of younger age (3-4 years), low children's leisure-time and sport index, low parental sport index, high WC and attending a kindergarten located in a disadvantaged city district. Interestingly, results indicated that WC is a better predictor of MPA than the well-established BMI in kindergartners. In contrast to previous studies [26, 35], no association was found between MPA and BMI, except for the test item "lateral jumping" ( $p=0.039$ ).

The current study findings indicated that there is a high variance for WC in this young age group, already. According to Schwandt et al. [57], the combination of having a low BMI and a high WC may cause an adverse health development. Epidemiological studies proposed to use WC measurements in clinical settings, already at pre-school 
Table 3 Motor performance ability test items (Median and IQR ${ }^{\mathrm{a}}$ ) of the total study sample stratified by BMI ${ }^{b}$ group (IOTF ${ }^{\mathrm{C}}$ cutoffs)

\begin{tabular}{llll}
\hline Test items & $\mathrm{n}$ & Median (IQR) & $P^{*}$ \\
\hline $\begin{array}{l}\text { One leg stand, floor contacts } \\
\text { Normal weight }\end{array}$ & 348 & $16.0(7.0$ to 30.0$)$ & 0.175 \\
$\begin{array}{l}\text { Overweight/obesity } \\
\text { Standing long jump, cm }\end{array}$ & 76 & $17.5(9.0$ to 30.0$)$ & \\
$\quad$ Normal weight & 348 & $86.5(68.0$ to 103.8) & 0.513 \\
$\quad$ Overweight/obesity & 76 & $83.0(65.0$ to 102.6) & \\
Lateral jumping, jumps & & & \\
$\quad$ Normal weight & 348 & $25.0(19.0$ to 31.0$)$ & $\mathbf{0 . 0 3 9}$ \\
$\quad$ Overweight/obesity & 76 & $22.0(14.0$ to 29.0) & \\
Shuttle run, s & & & \\
Normal weight & 348 & $10.5(9.3$ to 12.3) & 0.904 \\
Overweight/obesity & 76 & $10.7(9.2$ to 12.0) & \\
\hline
\end{tabular}

${ }^{*} P<0.05$; Mann-Whitney U-Test of motor ability performance test items between the modified BMI groups; significance printed in bold type

${ }^{\mathrm{a}} \mathrm{IQR}=$ Interquartile range

${ }^{\mathrm{b}} \mathrm{BMl}=$ Body mass index

${ }^{\mathrm{C}} \mathrm{OTTF}=$ International Obesity Task Force

age, as well as in clinical practice (i.e. medical health examinations) with older children [56, 69], to monitor abdominal obesity. As previously shown, WC is a good predictor of intra-abdominal fat distribution in children and adolescents [70]. Measurement of WC is easy and cost-effective and the measurement may provide decisive benefits in order to identify those children who seemingly have a higher risk to develop obesity-related diseases later in adulthood [69]. In addition, recent research provides evidence that high WC is associated with increased systolic blood pressure, low-density lipoprotein cholesterol and triacylglycerol and decreased high-density lipoprotein cholesterol [71].

The second main result of our study provided evidence that the social environment of the district of the kindergarten represented by the LSI was independently related to MPA and it seemed to be that there is an apparent influence by the kindergarten's location. In a previous study, we have already shown the influence of the (occupational) social environment shaping the risk of obesity in kindergarten teachers in their work environment [47]. Other studies reported about the neighborhood environment mostly in school children [72-74]. We suppose that this social area-level deprivation has a greater impact on children's health than previously assumed. This work provides evidence that together with WC and other child characteristics, the city's district and therefore the social environment of the district of the kindergarten, possibly affect children's motor performance ability which is linked to children's health. The study from Finn et al. [75] showed similar results as our study and pointed out that more than half of the variance in daily physical activity, was predicted by the kindergarten. The implementation of physical activity interventions has to begin as early as possible [76]. Kindergartens with their specific environment seem to play an underestimated role in health promotion in young children [45].

The present study assessed physical activity levels with self-administered standardized questionnaires [49] to parents, who had to report on their as well as on their child's specific physical activity levels. Adjusted for covariates, there was a significant correlation between children's sport index and parental sport index, as well as

Table 4 Motor performance ability test items (Median and $I Q R^{a}$ ) of the total study sample stratified by age and gender specific WC groups $^{c}$

\begin{tabular}{|c|c|c|c|}
\hline Test items & $\mathrm{n}$ & Median (IQR) & $P^{*}$ \\
\hline \multicolumn{4}{|l|}{ One leg stand, floor contacts } \\
\hline No risk < (90th percentile) & 375 & 16.0 (7.0 to 30.0$)$ & \multirow[t]{2}{*}{0.014} \\
\hline High risk of having MCRF (90th $-<97$ th percentile) & 49 & 26.0 (11.5 to 30.0$)$ & \\
\hline \multicolumn{4}{|l|}{ Standing long jump, cm } \\
\hline No risk <(90th percentile) & 375 & 87.0 (69.0 to 105.0$)$ & \multirow[t]{2}{*}{0.008} \\
\hline High risk of having MCRF (90th - <97th percentile) & 49 & 76.0 (56.0 to 91.0$)$ & \\
\hline \multicolumn{4}{|l|}{ Lateral jumping, jumps } \\
\hline No risk < (90th percentile) & 375 & 25.0 (19.0 to 31.0$)$ & \multirow[t]{2}{*}{0.003} \\
\hline High risk of having MCRF (90th - <97th percentile) & 49 & 20.0 (14.5 to 25.5$)$ & \\
\hline \multicolumn{4}{|l|}{ Shuttle run, s } \\
\hline No risk < (90th percentile) & 375 & 10.5 (9.3 to 12.2$)$ & \multirow[t]{2}{*}{0.126} \\
\hline High risk of having MCRF (90th - <97th percentile) & 49 & $11.1(10.0$ to 12.1$)$ & \\
\hline
\end{tabular}

${ }^{*} P<0.05$; Mann-Whitney U-Test of motor ability performance test items between the different WC groups; significance printed in bold type

${ }^{\mathrm{a}} \mathrm{IQR}=$ Interquartile range

${ }^{\mathrm{b}} \mathrm{WC}=$ waist circumference

${ }^{\mathrm{C}}$ Modified WC groups were conducted according to Schandt et al. (2008) 
Table 5 Motor performance ability test items (Median and IQR ${ }^{\mathrm{a}}$ ) of the total study sample stratified by the social environment of the district of the kindergarten (LSI ${ }^{\mathrm{b}}$ groups)

\begin{tabular}{|c|c|c|c|}
\hline Test items & $n$ & Median (IQR) & $P^{*}$ \\
\hline \multicolumn{4}{|c|}{ One leg stand, floor contacts } \\
\hline LSI low & 175 & 17.0 (9.0 to 30.0$)$ & 0.044 \\
\hline LSI high & 249 & 15.0 (7.0 to 30.0$)$ & \\
\hline \multicolumn{4}{|c|}{ Standing long jump, cm } \\
\hline LSI low & 175 & 83.0 (65.0 to 100.0$)$ & 0.043 \\
\hline LSI high & 249 & 89.0 (67.5 to 106.0) & \\
\hline \multicolumn{4}{|c|}{ Lateral jumping, jumps } \\
\hline LSI low & 175 & $24.0(19.0$ to 30.0$)$ & 0.726 \\
\hline LSI high & 249 & 24.0 (18.0 to 31.0$)$ & \\
\hline \multicolumn{4}{|c|}{ Shuttle run, s } \\
\hline LSI low & 175 & 10.9 (9.6 to 12.2$)$ & 0.129 \\
\hline LSI high & 249 & $10.4(9.2$ to 12.1$)$ & \\
\hline
\end{tabular}

${ }^{*} P<0.05$; Mann-Whitney U-Test of motor ability performance test items between the LSI groups; significance printed in bold type ${ }^{\mathrm{a}} \mathrm{IQR}=$ Interquartile range

${ }^{\mathrm{b}} \mathrm{LSI}$ is defined by Life Situation Index scores (based on employment/working life; education; social situation/heterogeneity and home environment) according to Pfeiffer et al. (2005); score ranges from -10 to +10 with 0 as median

between children's leisure-time index and the corresponding parental index. Additionally, low parental HPA was a significant predictor of childhood overweight/ obesity (data not shown). These findings are consistent with previous research provided by Taylor et al. [77], who found a positive relationship between parental activity and child's activity $(r=.17-.28)$. In addition, Eriksson et al. [78] found similar associations of parent-child physical activity relationships between 12-year-olds and their parents and proposed to focus on the family environment to promote physical activity in children. In particular, joint physical activity in parent-child pairs could have health benefits, especially for girls, older children, older parents and high income families [79].

Manipulative skills refer to motor skills involving an object. They are all about making certain movements to apply force in order to move objects. Common examples include throwing, catching, kicking, or striking. Noteworthy, the standardized testing battery we employed here is devoid of manipulative motor skill performance and as such selective in nature. This limits the generalizability of our findings with regard to motor performance. As expected, older children showed better performance in the MPA test items than younger children. Similar results were shown in the MoMo study [20, 30, 80]. Girls significantly performed better in the "one leg stand" than boys and 4-6-year-old children attending kindergartens in Mainz showed better results in the test items "one leg stand" and "lateral jumping" compared to children, who participated in the MoMo study. Furthermore, and in
Table 6 Determinants of below-average motor performance ability in kindergartners aged 3-6 years ${ }^{\text {a }}$

\begin{tabular}{|c|c|c|c|}
\hline Item & $\mathrm{OR}^{\mathrm{b}}$ & $95 \% \mathrm{Cl}$ for $\mathrm{OR}^{\mathrm{C}}$ & $P^{*}$ \\
\hline \multicolumn{4}{|l|}{ Children's age } \\
\hline $3-4$ & 2.81 & $1.00-7.86$ & 0.049 \\
\hline $5-6$ & 1.00 & & \\
\hline \multicolumn{4}{|l|}{ Parental sport index ${ }^{d}$} \\
\hline Low & 2.07 & $1.18-3.63$ & 0.011 \\
\hline High & 1.00 & & \\
\hline \multicolumn{4}{|l|}{ Children's sport index ${ }^{d}$} \\
\hline Low & 3.24 & $1.85-5.67$ & $<0.001$ \\
\hline High & 1.00 & & \\
\hline \multicolumn{4}{|l|}{ Children's leisure-time index ${ }^{d}$} \\
\hline Low & 2.09 & $1.14-3.85$ & 0.017 \\
\hline High & 1.00 & & \\
\hline Children's waist circumference SDS ${ }^{\mathrm{e}}$ & 1.41 & $1.01-1.95$ & 0.041 \\
\hline \multicolumn{4}{|c|}{ Social environment (LSI) of the district of the kindergarten ${ }^{f}$} \\
\hline Low & 2.72 & $1.29-5.75$ & 0.009 \\
\hline High & 1.00 & & \\
\hline
\end{tabular}

${ }^{\mathrm{a}}$ Only significant associations are displayed

${ }^{\mathrm{b}} \mathrm{OR}=$ Odds ratios

'OR and $95 \%$ confidence intervals $(\mathrm{Cl})$ are from multiple logistic regression analysis in which all independent variables were included simultaneously: Kindergarten teachers BMI, kindergarten teachers age, kindergarten teachers habitual physical activity, children's gender, children's age, children's migration background, educational level, parental BMI, parental habitual physical activity, children's body mass index standard deviation scores, social environment of the district of the kindergarten (LSI), children's screen time activities, children's physical activity level

${ }^{\mathrm{d}}$ Sport index and leisure-time index was derived from the habitual physical activity score conducted by Baecke et al. (1982). Scores were dichotomized. The lower the score, the more likely the participant had lower physical activity levels

eStandard deviation scores according to the UK 1990 reference by Cole et al. (1998)

${ }^{f} \mathrm{LSI}=$ Life situation index was conducted analogously to the study of Hoffmann et al. (2013)

${ }^{*} P \leq 0.05$

contrast to preliminary findings [65], the results of the "standing long jump" indicated no differences between BMI groups. This is in accordance with results of the KiMo project, presented by De Toia et al. [16].

The results of our study are limited due to the use of a self-reported questionnaire that may have led to a systematic bias towards the directions of more socially desirable answers for questions about physical activity and anthropometrics. Specifically, only one parent reported personal and children-specific physical activity and screen time, which may have led to some additional invalidity. Furthermore, our cross-sectional design limits our ability to draw conclusions about the direction of the associations and analysis of our logistic regression should not be regarded as a causal relationship between the dependent and the independent variable. Besides the statistical and administrative limitations it should be mentioned that the LSI was used to describe the social 
environment of the city district, where the kindergarten is located. Since the kindergarten is commonly located close to the place of residence, we cannot exclude that parental socio-economic factors are major contributors to the associations with the LSI. Even though the study focused on the social environment of the neighborhood around the kindergarten on child-specific influencing factors, potential confounding child specific variables like unhealthy diet, psychological factors or inadequate sleep were not assessed and should be considered in future studies.

\section{Conclusion}

The current findings supported the association between MPA and physical activity in kindergartners. Physical activity scores of the parents and the child were positively associated with the child's respective MPA. Although the correlation coefficients between the MPA items and the indices of physical activity in children were low, there were more profound differences between physically active children and those who were less physically active during their daily life. Furthermore, we found a significant association of WC and the social environment of the district of the kindergarten with MPA.

Our study suggests that in kindergartners 3- to 6-years of age, important influencing factors for below-average motor ability can be identified, already. Therefore, future studies may verify and target these factors to more effectively intervene in young children by promoting physical activity in order to prevent overweight/obesity as well as other negative consequences of physical inactivity.

\section{Abbreviations \\ ANOVA: Analysis of variance; BMI: Body Mass Index; CHSM: Children Health Study Mainz; HPA: Habitual Physical Activity; HPAQ: Habitual Physical Activity Questionnaire; IOTF: International Obesity Task Force; IRB: Institutional Review Board; KiGGS: German Health and Examination Survey of Children and Adolescents; LSI: Life situation index; MCRF: Multiple cardio-metabolic risk factors; MoMo: Motorik-Modul; MPA: Motor performance ability; OR: Odds ratio; SD: Standard deviation; SDS: Standard deviation scores; SEP: Socio- economic position; TV: Television; WC: Waist circumferences}

\section{Acknowledgements}

The authors would like to thank all of the children and their parents who participated in the study. The authors also thank Suzan Botzenhardt, Conny Brendel, Pavel Dietz and Sarah Breitbach who was involved in data collection.

\section{Authors' contributions}

SWH was involved in study design, data collection and data analysis. SWH, MD, MSU drafted manuscript. SWH, MD, MSU and PS evaluated and interpreted the data. PS is the principal investigator of this study, contributed to the study design and was also involved in statistical data analysis and writing the manuscript. All authors listed approved the final version of the manuscript.

\section{Funding}

This study was funded by grant 9312-74 712-0 from the Ministry of Education, Science, Youth and Culture of Rhineland-Palatinate and the inneruniversity research promotion program of the Johannes GutenbergUniversity of Mainz. The publication fees were funded by the German
Research Foundation (DFG) and the University of Bayreuth in the funding programme Open Access Publishing. The funders had no role in study design, data collection and analysis, decision to publish, or preparation of the manuscript.

\section{Availability of data and materials}

The data sets used and / or analyzed during the current study are available from the corresponding author on reasonable request.

\section{Ethics approval and consent to participate}

Permission was obtained to perform the study from the supreme authority; the department head of social issues, children, youth, school and health of the city of Mainz. The study protocol was finally approved by the Institutional Review Board of the city of Mainz and the data protection commissioner according to the State Data Protection Act of Rhineland Palatinate. Participation in this study was voluntary and all parents of participants provided written informed consent. To increase the level of anonymity, personal data collection was reduced to a minimum.

\section{Consent for publication}

Not applicable.

\section{Competing interests}

The authors declare that the research was conducted in the absence of any commercial or financial relationships that could be construed as a potential conflict of interest.

\section{Author details}

'Department of Sports Medicine, Disease Prevention and Rehabilitation, Faculty of Social Science, Media and Sport, Johannes Gutenberg-University Mainz, Albert-Schweitzer-Straße, 22, 55128 Mainz, Germany. ${ }^{2}$ Department of Sports Medicine / Sports Physiology, Institute of Sport Science, University of Bayreuth, Universitätsstraße 30, 95440 Bayreuth, Germany. ${ }^{3}$ Division of Pediatric Epidemiology, Institute of Medical Biostatistics, Epidemiology and Informatics, University Medical Center of the Johannes Gutenberg University Mainz, Obere Zahlbacher Straße 69, 55131 Mainz, Germany.

Received: 16 January 2019 Accepted: 3 December 2019

Published online: 06 January 2020

References

1. Hoffmann SW, Ulrich R, Simon P. Refined analysis of the critical age ranges of childhood overweight: implications for primary prevention. Obesity. 2012; 20(10):2151-4.

2. Lobstein T, Frelut ML. Prevalence of overweight among children in Europe. Obes Rev. 2003:4(4):195-200.

3. Monasta L, Batty GD, Cattaneo A, Lutje V, Ronfani L, Van Lenthe FJ, Brug J. Early-life determinants of overweight and obesity: a review of systematic reviews. Obes Rev. 2010;11(10):695-708.

4. De Onis M, Blossner M, Borghi E. Global prevalence and trends of overweight and obesity among preschool children. Am J Clin Nutr. 2010; 92(5):1257-64.

5. Australian Health Survey: First Results, 2011-124364.0.55.001. http://www. abs.gov.au/ausstats/abs@.nsf/Lookup/27D7FFFD3AEE46CCCA257AA30014 BFFA.

6. Collaboration NRF. Worldwide trends in body-mass index, underweight, overweight, and obesity from 1975 to 2016: a pooled analysis of 2416 population-based measurement studies in 128.9 million children. Lancet. 2017(390):2627-42.

7. Kuhl ESCL, Stark LJ. Obesity in preschoolers: behavioral correlates and directions for Treatmant. Obesity. 2012;20:3-29.

8. Suglia SFSR, Hsiao A, Wang YC, Rundle A, Link BG. Why the neighborhood social environment is critical in obesity prevention. J Urban Health. 2016; 93(1):206-12.

9. te Velde SJ, van Nassau F, Uijtdewilligen L, van Stralen MM, Cardon G, De Craemer M, Manios Y, Brug J, Chinapaw MJM. Energy balance-related behaviours associated with overweight and obesity in preschool children: a systematic review of prospective studies. Obes Rev. 2012;13(Suppl. 1):56-74.

10. Cappuccio FP, Taggart FM, Kandala NB, Currie A, Peile E, Stranges S, Miller MA. Meta-analysis of short sleep duration and obesity in children and adults. Sleep. 2008;31(5):619-26. 
11. Sahoo K, Sahoo B, Choudhury AK, Sofi NY, Kumar R, Bhadoria AS. Childhood obesity: causes and consequences. J Family Med Prim Care. 2015;4(2):187-92.

12. Larson NIWM, Story MT, Neumark-Sztainer DR. Home/family, peer, school, and neighborhood correlates of obesity in adolescents. Obesity (Silver Spring). 2013;21(9):1858-69.

13. McNeil LHKM, Subramanian SV. Social environment and physical activity: a review of concepts and evidence. Soc Sci Med. 2006;63(4):1011-22.

14. Baker $\mathrm{L}$, Olsen LW, Sorensen TI. Childhood body-mass index and the risk of coronary heart disease in adulthood. N Engl J Med. 2007;357(23):2329-37.

15. Bös K, Heel J, Romahn N, et al. Untersuchungen zur Motorik im Rahmen des Kinder- und Jugendgesundheitssurveys. Gesundheitswesen. 2002;64:80-7.

16. De Toia D, Klein D, Weber S, Wessely N, Koch B, Tokarski W, Dordel S, Struder $\mathrm{H}$, Graf C. Relationship between anthropometry and motor abilities at pre-school age. Obes Facts. 2009;2(4):221-5.

17. Lobstein T, Baur L, Uauy R. Obesity in children and young people: a crisis in public health. Obes Rev. 2004;5(Suppl 1):4-104.

18. Opper E, Worth A, Wagner M, Bös K. Motorik-Modul (MoMo) im Rahmen des Kinder und Jugendsurveys (KIGGS). Motorische Leistungsfähigkeit und körperlich-sportliche Aktivität von Kindern und Jugendlichen in Deutschland. Bundesgesundheitsblatt Gesundheitsforschung Gesundheitsschutz. 2007:50:879-88.

19. Kurth BM, Schaffrath Rosario A. The prevalence of overweight and obese children and adolescents living in Germany. Results of the German health interview and examination survey for children and adolescents (KiGGS). Bundesgesundheitsblatt Gesundheitsforschung Gesundheitsschutz. 2007;50(5-6):736-43.

20. Bös K, editor. Motorik-Modul. Eine Studie zur motorischen Leitungsfähigkeit und körperlich-sportlichen Aktivität von Kindern und Jugendlichen in Deutschland. Abschlussbericht zum Forschungsprojekt. 1edn ed. Baden-Baden: Nomos; 2009.

21. Opper E, Worth A, Bos K. Fitness of children--children's health. Bundesgesundheitsblatt, Gesundheitsforschung, Gesundheitsschutz. 2005; 48(8):854-62.

22. Bös K. Motorische Leistungsfähigkeit von Kindern und Jugendlichen. In: Schmidt W, Hartmann-Tews I, Brettschneider W-D, editors. Erster Deutscher Kinder- und Jugendsportbericht. Schorndorf: Hofmann; 2003. p. 85-109.

23. Castetbon K, Andreyeva T. Obesity and motor skills among 4 to 6-year-old children in the United States: nationally-representative surveys. BMC Pediatr. 2012;12:28.

24. Han A, Fu A, Cobley S, Sanders RH. Effectiveness of exercise intervention on improving fundamental movement skills and motor coordination in overweight/obese children and adolescents: a systematic review. J Sci Med Sport. 2017.

25. D'Hondt E, Deforche B, Vaeyens R, Vandorpe B, Vandendriessche J, Pion J, Philippaerts R, de Bourdeaudhuij I, Lenoir M. Gross motor coordination in relation to weight status and age in 5- to 12-year-old boys and girls: a cross-sectional study. Int J Pediatr Obes. 2011;6(2-2):e556-64.

26. Graf C, Koch B, Kretschmann-Kandel E, Falkowski G, Christ H, Coburger S, Lehmacher W, Bjarnason-Wehrens B, Platen P, Tokarski W, et al. Correlation between BMI, leisure habits and motor abilities in childhood (CHILT-project). Int J Obes Relat Metab Disord. 2004;28(1):22-6.

27. Morano M, Colella D, Caroli M. Gross motor skill performance in a sample of overweight and non-overweight preschool children. Int J Pediatr Obes. 2011;6(Suppl 2):42-6.

28. Cairney JHJ, Faught BE, Hawes R. Development coordination disorder and overweight and obeisty in children aged 9-14 y. Int J Obes. 2005;29:369-72.

29. Cawley J SK. Obesity and skill attainment in early childhood. NBER Working Paper Series 2008, 13997

30. Starker A, Lampert T, Worth A, et al. Motorische Leistungsfähigkeit - Ergebnisse des Kinder- und Jugendgesundheitssurveys (KiGGS). Bundesgesundheitsblatt, Gesundheitsforschung, Gesundheitsschutz. 2007:50:775-83.

31. Foulkes JDKZ, Fairclough SJ, Stratton G, O'Dwyer M, Ridgers ND, Foweather L. Fundamental movement skills of preschool children in Northwest England. Percept Mot Skills. 2015;121:260-83.

32. Rodrigues LP, Stodden DF, Lopes VP. Developmental pathways of change in fitness and motor competence are related to overweight and obesity status at the end of primary school. J Sci Med Sport. 2016;19(1):87-92.

33. Asendorpf JB, Teubel T. Motorische Entwicklung vom frühen Kindes- bis zum frühen Erwachsenenalter im Kontext der Persönlichkeitsentwicklung. Z Sportpsychol. 2009;16:2-16.

34. Bappert S, Bös K, Woll A. Motorische Leistungsunterschiede bei über- und normalgewichtigen Kindern im Vorschulalter. Haltung und Bewegung. 2003; 23:35-7.
35. Bös K, Bappert S, Tittlbach S, Woll A. Karlsruher Motorik-Screening für Kindergartenkinder (KMS 3-6). Sportunterricht. 2004:53:79-87.

36. Krombholz H. Bewegungsförderung im Kindergarten - Ergebnisse eines Modellversuchs. Teil 2: Ergebnisse der wissenschaftlichen Begleitforschung. Motorik. 2004;27(4):166-82.

37. Voelcker-Rehage C. Der Zusammenhang zwischen motorischer und kognitiver Entwicklung im frühen Kindesalter - Ein Teilergebnis der MODALIS-Studie. Deutsch Z Sportmed. 2005;56:358-63.

38. Weiß A, Weiß W, Stehle J, et al. Beinflussung der Haltung und Motorik durch Bewegungsförderungsprogramme bei Kindergartenkindern. Deutsch Z Sportmed. 2004;55:101-5.

39. Williams HG, Pfeiffer KA, O'Neill JR, Dowda M, Mclver KL, Brown WH, Pate RR. Motor skill performance and physical activity in preschool children. Obesity. 2008;16(6):1421-6.

40. Fisher A, Reilly JJ, Kelly LA, Montgomery C, Williamson A, Paton JY, Grant S. Fundamental movement skills and habitual physical activity in young children. Med Sci Sports Exerc. 2005;37(4):684-8.

41. Van Capelle A, Broderick CR, van Doorn N, Ward RE, Parmenter BJ. Interventions to improve fundamental motor skills in pre-school aged children: a systematic review and meta-analysis. J Sci Med Sport. 2017;20(7):658-66.

42. Burkhauser RV, Cawley J. Beyond BMl: the value of more accurate measures of fatness and obesity in social science research. J Health Econ. 2008;27(2):519-29.

43. Cattuzzo MT, Dos Santos HR, Re AH, de Oliveira IS, Melo BM, de Sousa MM, de Araujo RC, Stodden D. Motor competence and health related physical fitness in youth: a systematic review. J Sci Med Sport. 2016;19(2):123-9.

44. Savva SC, Tornaritis M, Savva ME, Kourides Y, Panagi A, Silikiotou N, Georgiou C, Kafatos A. Waist circumference and waist-to-height ratio are better predictors of cardiovascular disease risk factors in children than body mass index. Int J Obes Relat Metab Disord. 2000;24(11):1453-8.

45. Hoffmann SW, Tug S, Simon P. Child-caregivers' body weight and habitual physical activity status is associated with overweight in kindergartners. BMC Public Health. 2014;14:822.

46. Rapp K, Schick KH, Bode H, Weiland SK. Type of kindergarten and other potential determinants of overweight in pre-school children. Public Health Nutr. 2005;8(6):642-9.

47. Hoffmann SW, Tug S, Simon P. Obesity prevalence and unfavorable health risk behaviors among German kindergarten teachers: cross-sectional results of the kindergarten teacher health study (KTHS). BMC Public Health. 2013;13:927.

48. Kurth BM, Kamtsiuris P, Holling H, Schlaud M, Dolle R, Ellert U, Kahl H, Knopf $H$, Lange $M$, Mensink GB, et al. The challenge of comprehensively mapping children's health in a nation-wide health survey: design of the German KiGGS-study. BMC Public Health. 2008:8:196.

49. Baecke JA, Burema J, Frijters JE. A short questionnaire for the measurement of habitual physical activity in epidemiological studies. Am J Clin Nutr. 1982; 36(5):936-42.

50. Deforche B, Lefevre J, De Bourdeaudhuij I, Hills AP, Duquet W, Bouckaert J. Physical fitness and physical activity in obese and nonobese Flemish youth. Obes Res. 2003;11(3):434-41.

51. Vogels N, Westerterp KR, Posthumus DL, Rutters F, Westerterp-Plantenga MS. Daily physical activity counts vs structured activity counts in lean and overweight Dutch children. Physiol Behav. 2007:92(4):611-6.

52. Lampert $T$, Sygusch $R$, Schlack R. Use of electronic media in adolescence. Results of the German health interview and examination survey for children and adolescents (KiGGS). Bundesgesundheitsblatt, Gesundheitsforschung, Gesundheitsschutz. 2007;50(5-6):643-52.

53. WHO. Obesity: preventing and managing the global epidemic. World Health Organ Tech Rep Ser. 2000;894:i-xii, 1-253.

54. Sacerdote C, Ricceri F, Rolandsson O, Baldi I, Chirlaque MD, Feskens E, Bendinelli B, Ardanaz E, Arriola L, Balkau B, et al. Lower educational level is a predictor of incident type 2 diabetes in European countries: the EPICInterAct study. Int J Epidemiol. 2012;41(4):1162-73.

55. WHO. Physical status: the use and interpretation of anthropometry. In: Technical report series, vol. 854. Geneva: WHO; 1995.

56. Kromeyer-Hauschild K, Dortschy R, Stolzenberg H, Neuhauser H, Rosario AS. Nationally representative waist circumference percentiles in German adolescents aged 11.0-18.0 years. Int J Pediatr Obes. 2011;6(2-2):e129-37.

57. Schwandt P, Kelishadi R, Haas GM. First reference curves of waist circumference for German children in comparison to international values: the PEP family heart study. World J Pediatr: WJP. 2008;4(4):259-66.

58. McCarthy HD, Jarrett KV, Crawley HF. The development of waist circumference percentiles in British children aged 5.0-16.9 y. Eur J Clin Nutr. 2001;55(10):902-7. 
59. Cole TJ, Bellizzi MC, Flegal KM, Dietz WH. Establishing a standard definition for child overweight and obesity worldwide: international survey. BMJ. 2000; 320(7244):1240-3.

60. Cole TJ, Freeman JV, Preece MA. British 1990 growth reference centiles for weight, height, body mass index and head circumference fitted by maximum penalized likelihood. Stat Med. 1998;17(4):407-29.

61. Cole TJ, Freeman JV, Preece MA. Body mass index reference curves for the UK, 1990. Arch Dis Child. 1995;73(1):25-9.

62. Freeman JV, Cole TJ, Chinn S, Jones PR, White EM, Preece MA. Cross sectional stature and weight reference curves for the UK, 1990. Arch Dis Child. 1995;73(1):17-24

63. Taylor RW, Jones IE, Williams SM, Goulding A. Evaluation of waist circumference, waist-to-hip ratio, and the conicity index as screening tools for high trunk fat mass, as measured by dual-energy X-ray absorptiometry, in children aged 3-19 y. Am J Clin Nutr. 2000;72(2):490-5.

64. McCarthy HD, Ellis SM, Cole TJ. Central overweight and obesity in British youth aged 11-16 years: cross sectional surveys of waist circumference. BMJ. 2003;326(7390):624.

65. Hoffmann SW. The children health study of Mainz - research report of the children fitness Olympiad, vol. 39. Mainz: Johannes Gutenberg-Universität Mainz; 2011.

66. Pfeiffer U, Kemper J, Braun R, Metzger H, Wiesemann L, Kleinhans K. Sozialraumanalyse 2005. Berlin, Mainz: Empirica; 2005.

67. Cole TJ, Green PJ. Smoothing reference centile curves: the LMS method and penalized likelihood. Stat Med. 1992;11(10):1305-19.

68. Pan H, Cole TJ. LMS growth a Microsoft Excel add-in to access growth references based on the LMS method. Version 2.2. 2007. www. healthforallchildren.co.uk/.

69. Gläser N, Zellner K, Kromeyer-Hauschild K. Validity of body mass index and waist circumference to detect excess fat mass in children aged 7-14 years. Eur J Clin Nutr. 2011;65(2):151-9.

70. Goran MI, Lane C, Toledo-Corral C, Weigensberg MJ. Persistence of prediabetes in overweight and obese Hispanic children: association with progressive insulin resistance, poor beta-cell function, and increasing visceral fat. Diabetes. 2008;57(11):3007-12.

71. Craig LC, Love J, Ratcliffe B, McNeill G. Overweight and cardiovascular risk factors in 4- to 18-year-olds. Obesity facts. 2008;1(5):237-42.

72. Crawford DBK, Cleland V, Timperio A. Home and neighbourhood correlates of BMI among children living in socioeconomically disadvantaged neighbourhoods. Br J Nutr. 2012;107:1028-36.

73. Crawford DCV, Timperio A, et al. The longitudinal influence of home and neighborhood environments on children's body mass index and physical activity over 5 years. In J Obes. 2010;34:1177-87.

74. BeLue RFL, Rollins B, Colaco B. One size does not fit all: identifying risk profiles for overweight adolescent population subsets. J Adolesc Health. 2009;45:517-24.

75. Finn K, Johannsen N, Specker B. Factors associated with physical activity in preschool children. J Pediatr. 2002;140(1):81-5.

76. Hnatiuk J, Ridgers ND, Salmon J, Campbell K, McCallum Z, Hesketh K. Physical activity levels and patterns of 19-month-old children. Med Sci Sports Exerc. 2012;44(9):1715-20.

77. Taylor RW, Murdoch L, Carter P, Gerrard DF, Williams SM, Taylor BJ. Longitudinal study of physical activity and inactivity in preschoolers: the FLAME study. Med Sci Sports Exerc. 2009;41(1):96-102.

78. Eriksson M, Nordqvist T, Rasmussen F. Associations between parents' and 12-year-old children's sport and vigorous activity: the role of self-esteem and athletic competence. J Phys Act Health. 2008;5(3):359-73.

79. Dunton GF, Liao Y, Almanza E, Jerrett M, Spruijt-Metz D, Chou CP, Pentz MA. Joint physical activity and sedentary behavior in parent-child pairs. Med Sci Sports Exerc. 2012;44(8):1473-80.

80. Woll A, Kurth BM, Opper E, Worth A, Bos K. The 'Motorik-Modul' (MoMo): physical fitness and physical activity in German children and adolescents. Eur J Pediatr. 2011;170(9):1129-42.

\section{Publisher's Note}

Springer Nature remains neutral with regard to jurisdictional claims in published maps and institutional affiliations.

\section{Ready to submit your research? Choose BMC and benefit from:}

- fast, convenient online submission

- thorough peer review by experienced researchers in your field

- rapid publication on acceptance

- support for research data, including large and complex data types

- gold Open Access which fosters wider collaboration and increased citations

- maximum visibility for your research: over $100 \mathrm{M}$ website views per year

At BMC, research is always in progress.

Learn more biomedcentral.com/submissions 